\title{
Synthesis and Antimicrobial Activity of 2-R 5-oxo 5-H 6-carbohydrazin 7-phenyl 1,3,4-thiadiazolo-[3,2-a] Pyrimidine
}

\author{
REZA MORADIVALIKBONI ${ }^{1 *}$, \\ YULDASHBOY HOZHIBOEVY ${ }^{1}$ and ZABIALAH HEIDARNEZHAD ${ }^{2}$
}

'V.I.Nikitin Institute of Chemistry Academy of Sciences of the Republic of Tajikistan. 2Department of Chemistry,Andimeshk Branch, Islamic Azad University, Andimeshk , Iran

*Corresponding author E-mail: rmoradi02@yahoo.com

http://dx.doi.org/10.13005/ojc/290452

(Received: August 25, 2013; Accepted: October 19, 2013)

\begin{abstract}
The synthesis of 2-R 5-oxo 5-H 6 -carbohydrazin 7-phenyl 1,3,4-thiadiazolo-[3,2-a] pyrimidine is described. This compound exhibits a broad spectrum of antimicrobial action and can be useful in the search for new antimicrobial drugs. Reactions of 2- R 5 - Oxo 5-H 6-EthylCarboxilate 7-phenyl -1,3,4-Thiadiazolo-[3,2-a] pyrimidine with hydrazine produce 2-R 5-oxo 5-H 6-carbohydrazin 7-phenyl 1,3,4-thiadiazolo-[3,2-a] pyrimidine. The structures of the compounds obtained are set NMR, 13C, IR- spectroscopy.
\end{abstract}

Key words: Pyrimidine, Hydrazine, Synthesis, IR- spectroscopy, ${ }^{13} \mathrm{CNMR}$.

\section{INTRODUCTION}

1,3,4-thiadiazolo [3,2-a] pyrimidine system efficiently enhances the physiological activity of the molecule 1-3. This replacement occurs in the reactions of 1,3,4- thiadiazolo [3,2-a]pyrimidine derivatives with electrophiles4-5.Literature data on fused heterocycles with athiadiazolo [3,2-a] pyrimidine system anelated with an other ring are scarce.These include 1,3,4-thiadiazolo [3,2 -b] quinozalhaes,6-8 pyrazolol [3,4-e] 1,3,4-thiadiazolo [3,2 -alpyrimidines9 and 1,3,4-thiadiazolo [3 , 2-a] pyrido $\left[3,2\right.$, e]pyrimidines ${ }^{10}$.

Thioamides are mostly involved in reactions related to the nucleophilic activity of these compounds, where by sulfuror nitrogen atoms act as reactive centers. In particular, thioamides readily react with alkyl halogenides and alkyl sulfides with the formation of S-alkyl-isothiuronium salts ${ }^{11}$.

With a view to investigation of the reaction cability of 1,3,4-thiadiazolo-[3,2-a]pyrimidine derivatives and the search for new physiological compounds in this group, we have synthesized a series of thiuronium salts from various thioamides. Derivatives of 1,3,4-thiadiazolo [3,2-a]pyrimidine are potential biologically active substances,12-15. The introduction of ketene dithioacetal fragments into the molecules makes it possible to synthesize heterocyclic systems with various functional groups ${ }^{16,17}$. 


\section{Synthesis 2-R 5-oxo 5-H 6 -carbohydrazin} 7-phenyl 1,3,4-thiadiazolo-[3,2-a]

Pyrimidineis carried out int wo stages. The first step we have synthesized 2-R5-oxo5-H6EthylCarboxilate7-phenyl [1,3,4]thiadiazolo[3,2,-a] pyrimidine with Use from 2- R 5-amino 1,3,4thiadiazole and ethyl 2- formyl 3- okco 3- phenyl propanoate (Figure 1).

The Next Step we have synthesized 2-R 5-oxo 5-H 6 -carbohydrazin 7-phenyl 1,3,4thiadiazolo-[3,2-a] pyrimidine from 2-R5-oxo5-H6EthylCarboxilate7-phenyl [1,3,4]thiadiazolo[3,2,-a] pyrimidineand hydrazine in present solvent alcohol ethanol (Figure 2).

\section{RESULT AND DISCUSSION}

At first, we have tried synthes is of 2- $R$ 5-oxo 5-H 6-carbohydrazin 7-phenyl -1,3,4thiadiazolo $[3,2-a]$ pyrimidine with use $2-\mathrm{R}$ 5-oxo 5-H 6-ethylcarboxylate 7-phenyl 1,3,4-thiadiazolo $[3,2-a]$ pyrimidine andhydrazine in variousAlcohol. But it looks better in the alcohols with less carbon and hydrogen.Such as methanol or ethanol.

To show the generality and applicability of this procedure, we treated a wide variety of $2-\mathrm{R}$ 5-oxo 5-H 6-ethylcarboxylate 7-phenyl 1,3,4thiadiazolo [3,2-a] pyrimidine and hydrazine in the presence of alcohol ethanol at $78^{\circ} \mathrm{C}$ and obtained the

Table 1: Synthes is of 2- R 5-oxo 5-H 6-carbohydrazin 7-phenyl -1,3,4-thiadiazolo [3,2-a] pyrimidine with 2-R 5-oxo 5- $\mathrm{H} 6$-ethylcarboxylate 7-phenyl $1,3,4$ - thiadiazolo [3,2-a] pyrimidine and hydrazinea

Entry hydrazine Time(h) Yieldb(\%)

a Reactions were carried out with 2- R 5-oxo 5-H 6-ethylcarboxylate 7-phenyl 1,3,4-thiadiazolo [3,2-a] pyrimidine and hydrazine $\mathrm{b}$ Yields refer to isolated pure products 
$\overbrace{\mathrm{S}}^{\mathrm{N}-\mathrm{N}} \mathrm{NH}_{2}^{+}$

(1)<smiles>CCOC(=O)C(=COC)C(=O)c1ccccc1</smiles>

(2)<smiles>[R]c1nn2c(=O)c(C(=O)OCC)c(-c3ccccc3)nc2s1</smiles>

(3)

$\mathrm{R}:\left(\mathrm{H}, \mathrm{CH}_{3}, \mathrm{Ph}-, \mathrm{PhCH}_{2}, \mathrm{Br}\right)$

Fig. 1: Synthes is of 2-R7-phenyl 6- ethylcarboxylate 5-oxo 5-H 1,3,4-thiadiazolo [3,2- a]pyrimidine<smiles>[R]c1nn2c(=O)c(C(=O)OC)c(-c3ccccc3)nc2s1</smiles>

(3)<smiles>[R]c1nn2c(=O)c(C(=O)NN)c(-c3ccccc3)nc2s1</smiles>

(4)

(5)

$\mathrm{R}:\left(\mathrm{H}, \mathrm{CH}_{3}, \mathrm{Ph}-, \mathrm{PhCH}_{2}, \mathrm{Br}\right)$

Fig. 2: Synthes is of 2- R 5-oxo 5-H 6-carbohydrazin7-phenyl -1,3,4-thiadiazolo [3,2-a]pyrimidine

desirable products in good to excellent yields (Table 1).

\section{EXPERIMENTAL}

A mixture of 2-R 5-oxo 5-H 6-ethylcarboxylate 7-phenyl 1,3,4- thiadiazolo [3,2-a] pyrimidine (1 $\mathrm{mmol})$,hydrazine (1 $\mathrm{mmol}$ ) was stirred magnetically at $780 \mathrm{C}$ and the progress of the reaction was monitored by thin-layer chromatography (TLC). The reaction mixture was filtered .In all the cases, the product obtained after the usual work up gave satisfactory spectral data ${ }^{18-19}$.

For example, 2-CH3 5-oxo 5-H 6-ethylcarboxylate 7-phenyl 1,3,4- thiadiazolo [3,2-a] pyrimidine (1 mmol-0.314gr),hydrazine (1 mmol- $0.032 \mathrm{gr}$ ) reated to gether in alcohol ethanol at 78 oC.And the product is obtained in $87 \%$ yield.
2-H 5-oxo 5-H 6-carbohydrazin 7-phenyl -1,3,4thiadiazolo [3,2-a] pyrimidine:1H NMR (400 MHz, $\left.\mathrm{CDCl}_{3}, \delta \mathrm{ppm}\right): 4.35(\mathrm{~s}, 2 \mathrm{H}, \mathrm{NH} 2)$; 7.14-7.30 $(5 \mathrm{H}$, $\mathrm{Ph}) ; 7.50$ (S, H):9.85 (s, H, NH) -13C NMR (100 $\mathrm{MHz}, \mathrm{CDCl} 3, \delta \mathrm{ppm}): 118(\mathrm{C}), 126,4(\mathrm{CH}), 126,4$ $(\mathrm{CH}), 128(\mathrm{CH}), 128.7(\mathrm{CH}), 128.7(\mathrm{CH}), 136.9(\mathrm{C}), 140$ $.3(\mathrm{CH}), 162,1(\mathrm{C}), 163(\mathrm{C}), 165.9(\mathrm{C}), 168(\mathrm{C})$.

\section{CONCLUSIONS}

in the various alcohol have been employed as a mild and highly efficient solvent system for the convenient preparation of $2-\mathrm{R} 5$-oxo $5-\mathrm{H}$ 6-carbohydrazin 7-phenyl -1,3,4-thiadiazolo [3,2-a] pyrimidine in excellent yields from 2- $\mathrm{R} 5$-oxo $5-\mathrm{H}$ 6-ethylcarboxylate 7-phenyl 1,3,4- thiadiazolo $[3,2-a]$ pyrimidine and hydrazine. The advantages include low cost, mild reaction conditions and reactions carried out at room temperature with excellent yields.

\section{REFERENCES}

1. M.Suiko and K.Maekawa, Agric. Biol.Chem., 41: 2047 (1977).
2. M.Suiko, E.Taniguchi, K.Maekawa, and M.Eto, Agric.BioL Chem., 43: 741 (1979). 
3. M.Suiko, E.Taniguchi, K.Maekawa, and M.Eto, BioL Chem., 43: 747 (1979).

4. S.Sh.Shukurov, M.A.Kukaniev, I.M.Nasyrov, L.S.Zakharov, and R.A.Kamkhanov, Zh.Obshch.ghim., 63: 2320 (1993) [Russ.J.Gen.Chem., 1993, 63 (Engl. Transl.)].

5. S.Sh.Shukurov, M.A.Kukaniev, 1.M.Nasyrov, L.S.Zakharov, and R.A.Karakhanov, lay.Akad. Nauk, Set.Khim., 908 (1994) . [Russ.Chem. BAIL, t994, 43: 854 (Engl.Transl.) L.

6. A.S.Shawali, A.O.Abdelhamid, H.M. Hassaneen and A.Shetta, J.HeteroeycL Chem., 19: 73 (1982).

7. A.O.Abdelhamid, H.M.Hassaneen, I.M.Abbas, andA.S.Shawali, Tetrahedron, 38: 1527 (1938).

8. M.K.A.Ibrahim, Indian J.Chem., 28B: 120 (1989).

9. M.B.El-Ashmawy, I.A.Shehata, H.1. ElSubbagh and A.A.El-Eman, Gazz. Chim. Ital., 121: 113 (1991).
10. A.Santagati, M.Santagati, F.gusso, and G.Ronsisvalle,, I.tleterocycl.Chem., 25: 949 (1988).

11. The Chemistry of Sulfur-Containing Organic Compounds [inRussian], Khimiya, Moscow (1988).

12. Pat.2712932, Germany, RZhKhim., 9.0.171P (Russ.Transl.) (1980).

13. Pat.4742063 USA, RZhKhim., 1.0.401P (in Russian) (1989).

14. Pat.4866064 USAI RZhKhim., 7.0384P (in Russian) (1991).

15. M.Suiko and K.Maekawa, Agric.Biol.Chem., 41: 2042 (1977).

16. Y.Tominaga, J.Heterocycl.Chem., 26: 1167 (1989).

17. H.Junjappa, H.Ila, and C.V.Asokan, Tetrahedron, 46: 5423 (1990).

18. F.A.O. Adekunle, B. Semire and O.A. Odunula, Orient J. Chem., 29(3): 945-951 (2013).

19. Om Prakash, S.A. Iqbal and G. Jacob, Orient. J. Chem., 29(3): 1079-1084 (2013). 